\title{
Bacterial colonization and granulocyte activation in chronic maxillary sinusitis in asthmatics and non-asthmatics
}

\begin{abstract}
Correspondence
Livije Kalogjera

kalogjera@sfzg.hr
\end{abstract}

Received 23 February 2009

Accepted 6 May 2009

\author{
Kreso Zurak, ${ }^{1}$ Davor Vagić, ${ }^{1}$ Petar Drvis, ${ }^{1}$ Carmen Prohaska Potocnik, ${ }^{2}$ \\ Senka Dzidic ${ }^{3}$ and Livije Kalogjera ${ }^{1}$ \\ ${ }^{1}$ Department of Otorhinolaryngology/Head \& Neck Surgery, University Hospital 'Sestre \\ Milosrdnice', Zagreb, Croatia \\ ${ }^{2}$ Department of Clinical Microbiology, University Hospital 'Sestre Milosrdnice', Zagreb, Croatia \\ ${ }^{3}$ Department of Molecular Genetics, 'Rudjer Boskovic' National Institute, Zagreb, Croatia
}

The impact of bacterial colonization on the severity and pattern of chronic inflammation in rhinosinusitis is not clear. In this study, it was hypothesized that bacterial colonization of the sinus mucosa would have a greater impact on inflammatory response modulation in asthmatic patients than in non-asthmatic patients with chronic rhinosinusitis. In order to test this hypothesis, granulocyte activation was measured and related to bacteria identified in the sinus lavage. Lavages from the maxillary sinuses of 21 asthmatic and 19 non-asthmatic patients with chronic rhinosinusitis (CRS) were microbiologically examined for aerobic and anaerobic growth. Eosinophil cationic protein (ECP), an eosinophil activation marker, and myeloperoxidase (MPO), a neutrophil activation marker, were measured in the sinus lavages. Bacteria were recovered in 20/32 samples from the asthmatics and in 21/33 samples from the non-asthmatics.

Gram-positive aerobes and anaerobes were slightly more common than Gram-negative bacteria. A different bacterial profile was found when comparing Gram-negatives between the groups. Concentrations of MPO were significantly higher in samples with bacterial recovery from asthmatic patients, compared to sterile samples of both groups. Concentrations of ECP in the samples from asthmatic patients were significantly higher than in the controls, with no significant difference related to bacterial colonization. Bacterial colonization in chronically inflamed sinuses may have an impact on neutrophil granulocyte activation in patients with bronchial asthma, which was not confirmed for patients with CRS without asthma.

\section{INTRODUCTION}

Chronic rhinosinusitis (CRS) has been defined as a persistence of two or more sinusitis-related symptoms for more than 12 weeks, confirmed by local objective signs (Fokkens et al., 2007). As many host-related and environmental factors associated with CRS have been identified, the aetiology of the disease remains unclear. Asthma and eosinophilia have been recognized as predisposing factors for extensive sinus disease based on computed tomography (CT) scan severity scores (Newman et al., 1994). Although bacteria are often detected in CRS, their role in the severity and pattern of inflammation is not clear. In a study where bacteria were cultivated in $88 \%$ of the sinus samples from patients operated upon for CRS, inflammation was confirmed microscopically in only $11 \%$ (Robinson et al.,

Abbreviations: COPD, chronic obstructive pulmonary disease; CRS, chronic rhinosinusitis; CT, computed tomography; ECP, eosinophil cationic protein; MPO, myeloperoxidase.
2005). The growth of middle meatal cultures collected at sinus surgery was significantly related to the severity of nasal obstruction and sinus CT scores in the asthmatics with CRS, but not in the CRS patients with small airways disease (Ragab et al., 2007), suggesting that asthma may lead to a different response to bacteria colonizing the sinuses. However, data from the lower airways suggest that the pattern of bacterial colonization in the bronchi might play a role in inflammatory cells activation in chronic bronchitis and in chronic obstructive pulmonary disease (COPD), not only in exacerbation, but also in the stable phase (Sethi et al., 2006).

It has been suggested that the response to bacterial products (DNA, toxins, antigens, superantigens) may modify the inflammation pattern and severity in allergy and asthma in two directions: protection or reduction versus enhancement of the allergic inflammation (Renz \& Herz, 2002). This bidirectional impact of bacteria is dependent on the timing of exposure and antigens 
involved, acting differently on the hypothesized $\mathrm{T}$ helper (Th)1/Th2 cell balance. Recent evidence in vitro suggested that the Th2-polarized response may have a negative impact on the innate immune host response to bacteria (Rate et al., 2009; Ramanathan et al., 2008). However, there are no studies in vivo that have analysed inflammatory cells activation related to bacterial colonization of the sinuses in CRS. This study was conducted in order to identify the pattern and intensity of the local granulocyte response to bacterial colonization in CRS, comparing asthmatics and non-asthmatics.

\section{METHODS}

Study population. The study was conducted with a group of 21 asthmatic (mean age 37.21 years, range 18-63) and 19 non-asthmatic (mean age 41.31 years - range 18-62) patients with CRS, who were scheduled for endosinusal treatment for persisting symptoms following unsuccessful long-term conservative treatment, and in 3 cases, surgical treatment. Medical treatment included topical nasal steroids, nasal saline lavages and, in most of the patients, long-term low dose macrolides, and, upon exacerbation, short-course antibiotics. The three cases were the only nasal polyp patients, with small polyp recurrence within the middle meatus (two patients from the asthma group and one from the non-asthma group).

Study design and inclusion/exclusion criteria. All patients gave their informed consent and the study was approved by the ethics committee of University Hospital 'Sestre Milosrdnice', Zagreb. Inclusion criteria were: more than 12 weeks of CRS symptoms/ endoscopy/radiology, criteria established in a European position paper (EPOS) on rhinosinusitis and nasal polyps (Fokkens et al., 2007) plus an additional $>10 \mathrm{~mm}$ mucosal thickening in at least one maxillary sinus on sinus CT, and, for the asthma group, mild to moderately severe asthma. Patients with systemic steroid or antibiotic treatment within the 4 weeks before enrolment, recent upper respiratory infection, suspected sinusitis of dental origin, severe asthma, increased C-reactive protein and those with nasal polyps out of middle meatus at endoscopy were excluded. As all of the patients had received long-term nasal steroids during the previous year, they were asked to stop nasal topical steroid treatment 2 weeks before antrostomy. Asthmatics were allowed to take their medication, including inhaled steroids.

Procedures and assessment techniques. After disinfection of the nasal vestibule and inferior meatus with ethanol, a sterile trocar was introduced into the maxillary sinus by unilateral or bilateral inferior maxillary antrostomy under local anaesthesia, and $30 \mathrm{~s}$ after injection of $5 \mathrm{ml}$ saline into the sinus, lavage was aspirated into a syringe, and samples sent for bacteriological and cellular marker analysis. Samples for cellular marker determination were stored at room temperature for $2 \mathrm{~h}$, centrifuged at $1000 \mathrm{~g}$ for $10 \mathrm{~min}$ and placed in a refrigerator at $-20{ }^{\circ} \mathrm{C}$. Eosinophil cationic protein (ECP) was analysed by fluoroenzyme immunoassay and myeloperoxidase (MPO) by radioimmunoassay.

Bacteriological samples were transported to the Microbiology Laboratory (Department of Clinical Microbiology, University Hospital 'Sestre Milosrdnice') for routine cultivation of bacteria. Samples were inoculated onto blood agar, chocolate agar, blood agar containing nalidixic acid and MacConkey agar plates for growth of aerobic and facultative organisms. They were incubated at $37{ }^{\circ} \mathrm{C}$ aerobically (MacConkey agar) or under $5 \%$ carbon dioxide (blood agars) and examined at 24 and $48 \mathrm{~h}$. For anaerobes, the sample was plated onto Schaedler agar (vitamin $\mathrm{K}_{1}$-enriched blood agar) and brain heart agar with nalidixic acid. After $48 \mathrm{~h}$ they were cultured in thioglycollate broth and any growth in this broth was subcultured into blood agar, and incubated both aerobically and anaerobically. Aerobic and anaerobic bacteria were identified by techniques described (Koneman et al., 1997). The lower limit of culture detection was approximately 100 c.f.u. (ml sample $)^{-1}$.

Statistical analysis. The normality of distribution was tested using the Smirnoff-Kolmgorov test. Student's $t$-test was used to detect the difference in levels of cellular activation markers between the groups for parameters demonstrating normal distribution, or the MannWhitney $\mathrm{U}$ test was used if the data did not show normal distribution. Correlations were calculated with the paired-samples correlation test and the Spearman rank correlation test. The statistical significance of the difference in the prevalence of bacteria recovered between the groups was calculated by the chi-square test using the Yates's correction. All conclusions were based on a significance level of $P<0.05$.

\section{RESULTS AND DISCUSSION}

\section{Bacteriology}

Bacterial growth was present in 20 of the $32(62.5 \%)$ lavage specimens from the asthmatic patients and in 21 of the 34 $(61.7 \%)$ from the non-asthmatic patients. Pathogens isolated in both groups are presented in Table 1 . Polymicrobial growth was recorded in approximately $20 \%$ of samples in both groups.

The recovery rate from the samples of chronic maxillary sinusitis for both aerobic and anaerobic bacteria, varied in different studies from $45 \%$ (Paju et al., 2003) to $92 \%$

Table 1. Bacterial strains detected in sinus lavages from asthmatic and non-asthmatic patients

Data are presented as the total number of strains recovered.

\begin{tabular}{|lccc|}
\hline Strain & \multicolumn{3}{c|}{ No. of strains } \\
\cline { 2 - 4 } & Asthmatics & $\begin{array}{c}\text { Non- } \\
\text { asthmatics }\end{array}$ & Total \\
\hline Staphylococcus aureus & 7 & 5 & 12 \\
Pseudomonas aeruginosa & 4 & 0 & 4 \\
Coagulase-negative & 0 & 3 & 3 \\
Staphylococcus & & & \\
Klebsiella species & 0 & 3 & 3 \\
Haemophilus influenzae & 0 & 2 & 2 \\
Streptococcus pneumoniae & 0 & 1 & 1 \\
Serratia marcescens & 2 & 0 & 2 \\
Propionibacterium species & 4 & 4 & 8 \\
Peptostreptococcus species & 3 & 2 & 5 \\
Streptococcus agalactiae & 1 & 0 & 1 \\
Veillonella parvula & 0 & 2 & 2 \\
Proteus mirabilis & 0 & 1 & 1 \\
Commensals & 4 & 3 & 7 \\
Total & 25 & 26 & 51 \\
\hline
\end{tabular}


(Brook, 1989), and is dependent on adequate sampling, cultivating and detection techniques. Gram-positive aerobes and anaerobes are much more common than Gramnegative bacteria, while previous surgery predisposes for an increased rate (up to $25 \%$ ) of Gram-negative bacteria (Brook \& Frazier, 2001). The recovery rate for aerobic bacteria in our study was similar to that found in the literature. Anaerobes were isolated in approximately $1 / 3$ colonized samples for both groups. The recovery rate for anaerobes from the aspirates in CRS varied from 21 (Newman et al., 1994) to $88 \%$ (Brook, 1989) in the literature. Such variability in the recovery rates of anaerobes is probably more related to the methodology of sampling (Karma et al., 1979; Brook, 1989) than the sensitivity of detection techniques, like PCR (Paju et al., 2003). The high rate of Gram-negative bacteria in our patients (in 12/41 colonized samples), may be attributed to the long-term courses of antibiotics targeting Grampositive bacteria, and, in some patients, colonization from the steroid spray nasal tips and nasal saline washings. The previous surgery was the predisposing factor in $2 / 3$ patients in our study who had been operated upon. The difference between the recovery rate, the rates of Gram-positive, Gram-negative and anaerobic bacteria and polymicrobial growth between the groups was not significant.

Interestingly, asthmatics and non-asthmatics had a completely different pattern of Gram-negative bacteria (100\% dissimilarity). Strains from the asthmatics (Pseudomonas, Serratia) resembled a nosocomial pattern, also in the antimicrobial resistance, while in non-asthmatics, predominantly Haemophilus and Klebsiella were found. Pseudomonas was found in three samples from the two patients who had been previously operated upon, inducing marked granulocyte activation, which was not the case with Serratia. We may speculate that the asthmatics had greater exposure to the nosocomial bacteria found in their samples (due to previous surgery and asthma control visits), as courses of antibiotic treatment were not more common in the asthma group. The asthmatics were also on higher doses of steroids, as they were treated both with nasal and inhaled steroids, and were probably more compliant to nasal steroid treatment; however, there is no evidence that steroid treatment may lead to changes in bacterial pattern in the sinuses. Haemophilus and Klebsiella, which were found in samples from non-asthmatic patients, are more common respiratory pathogens, and they did not induce marked granulocyte activation in these samples. We may speculate that those bacteria, more often found in acute rhinosinusitis, remained in low numbers and were not eradicated after acute exacerbations. Staphylococcus aureus was the most common Gram-positive strain in both groups, and the microbial pattern of anaerobes was similar between the groups.

\section{Granulocyte activation markers in the sinus lavage}

The data from the samples from the asthma group (but not from the non-asthma group) passed the SmirnoffKolmgorov test for normal distribution; however, due to the skewed distribution curve and small sample size, our biostatistician suggested the use of non-parametric tests for all calculations, so the Mann-Whitney U test was used for all comparisons between the groups. According to bacteriology, lavages were divided according to sterile and colonized (including commensals), and by asthmatics and nonasthmatics groups, forming four subgroups. Table 2 summarizes granulocyte marker (ECP and MPO) concentrations in all four subgroups.

ECP levels in both asthmatic groups were significantly higher than in the non-asthmatics group (Fig. 1). The difference between colonized and sterile asthmatics was not significant. MPO levels were significantly higher in the colonized than in the sterile samples from asthmatics and non-asthmatics (Fig. 2) $(P=0.004$, Man-Whitney U test). In non-asthmatics ECP and MPO were not significantly different between colonized and sterile lavages. In most of the cases of non-asthmatics with CRS, bacterial presence did not activate leukocytes and the median values of not only ECP, but also MPO, values were much lower than in

Table 2. Concentration of ECP and MPO from lavages of asthmatic and non-asthmatic patients with CRS presented as the median and $95 \%$ confidence intervals $(95 \% \mathrm{Cl})$ of median

The significance of the difference between colonized and sterile lavages is marked with $S$ for significant and NS for non-significant (Mann-Whitney $\mathrm{U}$ test); all conclusions were based on a significance level of $P<0.05$.

\begin{tabular}{|llccc|}
\hline Sample & & Median & $\mathbf{9 5}$ \% CI of median & $\boldsymbol{P}$ \\
\hline ECP asthma $\left(\mu \mathrm{g} \mathrm{l}^{-1}\right)$ & Colonized & 50.55 & $3.07-202.30$ & NS \\
& Sterile & 30.45 & $2.00-87.6$ & \\
ECP non-asthma $\left(\mu \mathrm{g}^{-1}\right)$ & Colonized & 2.6 & $2.00-28.6$ & NS \\
& Sterile & 2.00 & $2.00-37.2$ & \\
MPO asthma $\left(\mu \mathrm{g} \mathrm{l}^{-1}\right)$ & Colonized & 729.85 & $60.1-1200$ & $\mathrm{~S}$ \\
& Sterile & 134.60 & $6.8-634$ & \\
MPO non-asthma $\left(\mu \mathrm{g}^{-1}\right)$ & Colonized & 27.00 & $9-1023$ & NS \\
& Sterile & 13.00 & $5.1-542$ & \\
\hline
\end{tabular}




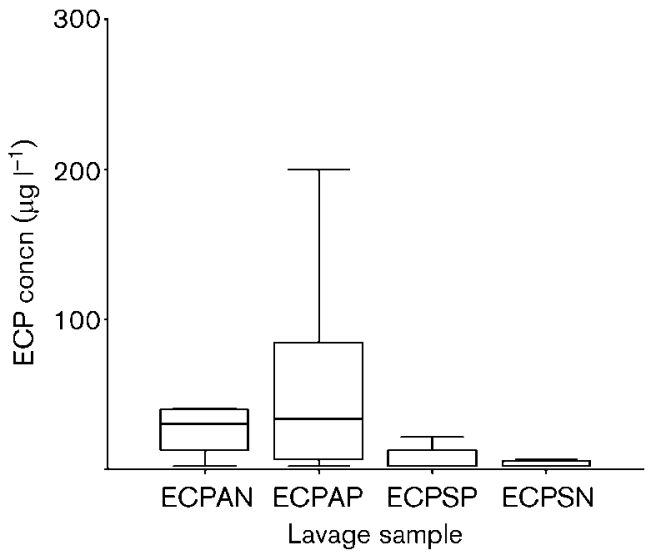

Fig. 1. Concentration of ECP $\left(\mu \mathrm{g} \mathrm{I}^{-1}\right)$ in colonized (ECPAP) and sterile (ECPAN) sinus lavages from asthmatics, and colonized (ECPSP) and sterile (ECPSN) sinus lavages from non-asthmatics. Data are presented as boxplots showing medians and interquartile ranges.

the asthmatics group. The median value of ECP in the colonized and sterile lavages for the asthmatic patients was almost the same (33.65 and $30.45 \mu \mathrm{g} \mathrm{l^{-1 }}$, respectively). However, almost $30 \%$ of samples from the asthmatic patients with colonized sinuses had $>150 \mu \mathrm{g} \mathrm{l}^{-1}$, compared to $<10 \%$ of samples from those with sterile sinuses. However, although the mean MPO level in samples from non-asthmatic patients was much higher in the infected sinuses, the median was almost the same in infected and sterile samples, and $4 / 21$ infected samples had $<50 \times$ median value and $3 / 13$ sterile samples had $<20 \times$ median value. The correlation between ECP and MPO was significant only in the infected asthmatics subgroup $(P=0.709, P<0.0001$, Spearman rank correlation test).

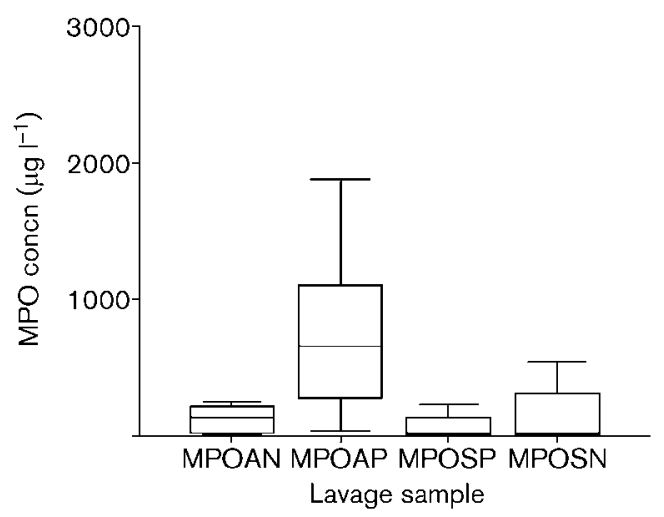

Fig. 2. Concentration of MPO $\left(\mu \mathrm{gl}^{-1}\right)$ in colonized (MPOAP) and sterile (MPOAN) sinus lavages from asthmatics, and colonized (MPOSP) and sterile (MPOSN) sinus lavages from nonasthmatics. Data are presented as boxplots showing medians and interquartile ranges.
Similarly to our findings, a significant correlation between ECP and MPO, but not related to bacterial growth, has been found in the bronchoalveolar lavage of the allergic and non-allergic asthmatics (Frangova et al., 1996) and chronic bronchitis patients (White et al., 2003).

The data from the lower airways indicate that inflammation in the stable phase of COPD is influenced by bacterial colonization (Sethi et al., 2006), as well as exacerbation rate (Patel et al., 2004). Some earlier studies of COPD and chronic bronchitis have shown that bacterial presence, especially Streptococcus pneumoniae, significantly increased ECP and MPO in bronchial lavage even in the stable phase (Riise et al., 1995). Lower inflammatory cell activity and proinflammatory cytokines in the sputum were found in exacerbated COPD in those patients where bacteria were eradicated (White et al., 2003). The highest values of both granulocyte markers in our study were found in samples where Pseudomonas aeruginosa was cultivated (10-50 $\times$ median), followed by Staphyloccocus aureus (data not shown). Concentrations of MPO in the lavages where Streptococcus pneumoniae and Haemophilus influenzae (strains typical for exacerbations of CRS) were cultivated, were close to mean values (data not shown). Most of the studies on inflammation in CRS from the literature have focused on host-related factors, like differences between allergic and non-allergic states (Suzuki et al., 1999). Environmental or microbial impacts on the severity of CRS were not considered so important, as the disease is perceived more like a chronic inflammation than infection. During the past decade attention has been drawn to the impact of bacterial superantigens, presumably Staphylococcus aureus enterotoxins, on the severity of allergic inflammation, first in the skin (Bunikowski et al., 1999) and then in the airways (Conley et al., 2004). It was shown that the proportion of patients with specific IgE antibodies to Staphylococcus aureus enterotoxins increased with the severity of airway inflammation, and was much higher in patients with severe asthma and nasal polyps than in patients with the 'plain' CRS (Gevaert et al., 2005).

The results of our study confirmed the hypothesis that bacterial colonization may have an impact on local neutrophil activation in chronic maxillary sinusitis in asthmatic patients, as a specific subgroup among patients with CRS. The small number of patients, and the broad inclusion criteria, prevented us from proving a significant impact of certain bacterial antigens on eosinophil activation in the asthmatics, although the mean ECP level was much higher in the colonized samples. However, results indicate that eosinophilic inflammation is not downregulated by bacterial colonization (acting on hypothesized Th1/Th2 balance), on the contrary, significant correlation between ECP and MPO in samples with bacterial growth suggests a trend towards simultaneous activation of neutrophilic and eosinophilic granulocytes influenced by certain bacterial antigens and toxins. Colonization with Staphylococcus aureus and $P$. aeruginosa resulted in high 
granulocyte activation in our patients. Interestingly, these bacteria are also the main biofilm producers in the airways (Ramadan et al., 2005).

An impact of bacteria on leukocyte activation in nonasthmatics was not proven to be significant, but the sample size was too small to draw final conclusions. The results, so far, indicate that the impact of bacterial colonization on granulocyte activation in chronic inflammation is dependent on specific interaction of host and bacterial antigens, where asthma is one of the predisposing host-related factors leading to a stronger response of sinus mucosa to bacterial antigens and toxins.

\section{REFERENCES}

Brook, I. (1989). Bacteriology of chronic maxillary sinusitis in adults. Ann Otol Rhinol Laryngol 98, 426-428.

Brook, I. \& Frazier, E. H. (2001). Correlation between microbiology and previous sinus surgery in patients with chronic maxillary sinusitis. Ann Otol Rhinol Laryngol 110, 148-151.

Bunikowski, R., Mielke, M. E. \& Skarabis, H. (1999). Prevalence and role of serum IgE antibodies to Staphylococcus aureus-derived superantigens SEA and SEB in children with atopic dermatitis. J Allergy Clin Immunol 103, 119-124.

Conley, D. B., Tripathi, A., Ditto, A. M., Reid, K., Grammer, L. C. \& Kern, R. C. (2004). Chronic sinusitis with nasal polyps: staphylococcal exotoxin immunoglobulin E and cellular inflammation. Am J Rhinol 18, 273-278.

Fokkens, W. J., Lund, V. J. \& Mullol, J. on behalf of the European Position Paper on Rhinosinusitis and Nasal Polyps Group (2007). European position paper on rhinosinusitis and nasal polyps2007. Rhinology 45, (Suppl. 20), 1-139.

Frangova, V., Sacco, O., Silvestri, M., Oddera, S., Balbo, A., Crimi, E. \& Rossi, G. A. (1996). BAL neutrophilia in asthmatic patients - a byproduct of eosinophil recruitment. Chest 110, 1236-1242.

Gevaert, P., Holtappels, G., Johansson, S. G., Cuvelier, C., Cauwenberge, P. \& Bachert, C. (2005). Organization of secondary lymphoid tissue and local IgE formation to Staphylococcus aureus enterotoxins in nasal polyp tissue. Allergy 60, 71-79.

Karma, P., Jokipii, L., Sipilä, P., Luotonen, J. \& Jokipii, A. M. (1979). Bacteria in chronic maxillary sinusitis. Arch Otolaryngol 105, 386-390.

Koneman, E. W., Allen, S. D., Janda, W. M., Schreckenberger, P. C. \& Winn, W. C., Jr (1997). Color Atlas and Textbook of Diagnostic Microbiology, 5th edn. Philadelphia, PA: Lippincott.
Newman, L. J., Platts-Mills, T. A., Phillips, C. D., Hazen, K. C. \& Gross, C. W. (1994). Chronic sinusitis. Relationship of computed tomographic findings to allergy, asthma, and eosinophilia. JAMA 271, 363-367.

Paju, S., Bernstein, J. M., Haase, E. M. \& Scannapieco, F. A. (2003). Molecular analysis of bacterial flora associated with chronically inflamed maxillary sinuses. J Med Microbiol 52, 591-597.

Patel, I. S., Vlahos, I., Wilkinson, T. M., Lloyd-Owen, S. J., Donaldson, G. C., Wilks, M., Reznek, R. H. \& Wedzicha, J. A. (2004). Bronchiectasis, exacerbation indices, and inflammation in chronic obstructive pulmonary disease. Am J Respir Crit Care Med 170, 400-407.

Ragab, A., Clement, P. \& Vincken, W. (2007). Bacterial cultures of the middle meatus and bronchoalveolar lavage in chronic rhinosinusitis. ORL J Otorhinolaryngol Relat Spec 69, 85-91.

Ramadan, H. H., Sanclement, J. A. \& Thomas, J. G. (2005). Chronic rhinosinusitis and biofilms. Otolaryngol Head Neck Surg 132, 414-417.

Ramanathan, M., Jr, Lee, W. K., Spannhake, E. W. \& Lane, A. P. (2008). Th2 cytokines associated with chronic rhinosinusitis with polyps down-regulate the antimicrobial immune function of human sinonasal epithelial cells. Am J Rhinol 22, 115-121.

Rate, A., Upham, J. W., Bosco, A., McKenna, K. L. \& Holt, P. G. (2009). Airway epithelial cells regulate the functional phenotype of locally differentiating dendritic cells: implications for the pathogenesis of infectious and allergic airway disease. J Immunol 182, 72-83.

Renz, H. \& Herz, U. (2002). The bidirectional capacity of bacterial antigens to modulate allergy and asthma. Eur Respir J 19, 158-171.

Riise, G. C., Ahlstedt, S., Larsson, S., Enander, I., Jones, I., Larsson, P. \& Andersson, B. (1995). Bronchial inflammation in chronic bronchitis assessed by measurement of cell products in bronchial lavage fluid. Thorax 50, 360-365.

Robinson, S., Der-Haroutian, V., Grove, D., Rees, G. \& Wormald, P. J. (2005). Prevalence of pus in radiologically diseased sinuses in patients undergoing surgery for chronic rhinosinusitis. Otolaryngol Head Neck Surg 133, 181-184.

Sethi, S., Maloney, J., Grove, L., Wrona, C. \& Berenson, C. S. (2006). Airway inflammation and bronchial bacterial colonization in chronic obstructive pulmonary disease. Am J Respir Crit Care Med 173, 991-998.

Suzuki, M., Watanabe, T., Suko, T. \& Mogi, G. (1999). Comparison of sinusitis with and without allergic rhinitis: characteristics of paranasal sinus effusion and mucosa. Am J Otolaryngol 20, 143-150.

White, A. J., Gompertz, S., Bayley, D. L., Hill, S. L., O’Brien, C., Unsal, I. \& Stockley, R. A. (2003). Resolution of bronchial inflammation is related to bacterial eradication following treatment of exacerbations of chronic bronchitis. Thorax 58, 680-685. 